\section{O interno e o externo: o barão do Rio Branco revisitado}

\section{Rodrigo Goyena Soares [*]}

[*]Universidade de São Paulo — São Paulo (SP), Brasil.E-mail: rodrigo.goyenasoares@usp.br

ORCID: https://orcid.org/0000-0003-1389-0930

SANTOS, Luís Cláudio Villafañe G. Juca Paranhos: o Barão do Rio Branco. São Paulo: Companhia das Letras, 2018.
Resumo: Patrono da diplomacia brasileira, o barão do Rio Branco permanece unanimemente celebrado em discursos oficiais do Itamaraty ou, inclusive, em textos acadêmicos. Esta nova biografia do barão, escrita pelo diplomata e historiador Luís Cláudio Villafañe G. Santos, rediscute não apenas a personalidade de Rio Branco, assinalando contradições, mas, sobretudo, reinterpreta sua ação diplomática à frente do Ministério das Relações Exteriores. Particularmente, interessa a esta resenha discutir três temas amplamente tratados por Villafañe: a interdependência entre política interna e externa, o estabelecimento de uma - suposta - aliança não escrita com os Estados Unidos e a resolução pacífica das disputas lindeiras.

Palavras-chave: Barão do Rio Branco; Itamaraty; Política externa republicana.

Domestic and foreign affairs: the baron of Rio Branco revisited

Abstract: The Baron of Rio Branco, patron of the Brazilian diplomacy, remains unanimously acclaimed in Brazil's foreign office, the Itamaraty, or even in academic books. This new biography of the Baron, written by Luís Cláudio Villafañe G. Santos, a Brazilian diplomat and historian, not only reexplores the personality of Rio Branco, pointing out contradictions, but mainly reinterprets his diplomatic agency when in office. It is in the interest of this review to discuss three topics broadly analyzed by Villafañe: the interdependence between domestic and foreign policies, the establishment of an allegedly unwritten alliance with the United States and the peaceful resolution of frontier disputes.

Keywords: Baron of Rio Branco; Itamaraty; Foreign policy of the Brazilian Republic. 
$\mathrm{N}$ ão são poucas as anedotas que fizeram de José Maria da Silva Paranhos Júnior, o barão do Rio Branco (1845-1912), um personagem festejado de maneira praticamente unânime pela historiografia. Feito raro para um diplomata, a considerar que seus homólogos de maior prestígio — tais como Duarte da Ponte Ribeiro (1795-1878) e Paulino José Soares de Sousa (1807-1866), à época do Império; ou Oswaldo Aranha (1894-1960), San Tiago Dantas (1911-1964) e Azeredo da Silveira (1917-1990), na República — costumam figurar apenas tangencialmente na história dos grandes acontecimentos nacionais. Estudioso compulsivo da formação lindeira do Brasil, o barão do Rio Branco, pelo que conta a história, tinha nos mapas um pêndulo que ritmava sua vida política e biológica. Quando já velho e debilitado pelo consumo exagerado de tabaco e por uma alimentação tanto desequilibrada quanto irregular, era surpreendido por rotineiras visitas médicas, adormecendo nos volumes cartográficos que, pelo resto, consolidavam sua glória. "Ontem à noite, quis examinar mais de perto os pormenores de um mapa que desenrolei no chão e acabei por dormir em cima dele" (apud Lins, 1945, p. 622), teria dito o paciente, ainda despertando, a um médico cada vez mais preocupado.

No cotidiano das ruas, o barão teria gozado de igual prestígio. Não há capital brasileira que não carregue ao menos uma avenida, rua ou beco com o nome de Rio Branco. Quiçá de forma ainda mais expressiva, não houve presidente qualquer capaz de demover o povo brasileiro de sua principal celebração nacional, qual seja, o carnaval. Sequer nos difíceis anos de Arthur Bernardes (1922-1926), do Estado Novo (1937-1945) ou da ditadura escancarada (1968-1974) a proeza foi alcançada. Nisso Paranhos também teve êxito. Ou quase, porque, embora sua morte, em fevereiro de 1912, tenha levado o governo de Hermes da Fonseca (19101914) a postergar o reinado de Momo para meados do ano como manifestação de pesar nacional, a população não resistiu, e dois carnavais foram comemorados em um semestre apenas. De todas as formas, o quase feito terminou sendo um duplo feito.

A biografia de Paranhos escrita pelo diplomata e historiador Luís Cláudio Villafañe G. Santos apresenta um personagem diferente. Sem minimizar a importância do barão para a política externa brasileira, emerge das páginas de Villafañe um Rio Branco múltiplo, porque a um só tempo Juca, José Maria, Paranhos, Júnior e Barão. A enumeração de nomes ou apelidos não se presta apenas no sentido das fases biológicas do personagem, que o fizeram transitar de um Juca boêmio para um José Maria bacharel, a um Paranhos deputado e, em seguida, Júnior, porque agora diplomata, porém sob a silhueta de seu pai, o visconde do Rio Branco (1819-1880), para final e paradoxalmente ser um barão na República. Quando assumiu em 1902 a chancelaria, que ganhara havia pouco o nome de Itamaraty em referência ao palácio que passou a albergá-la, Rio Branco acumulava vasta experiência. Nesse sentido, a narrativa fundamentalmente cronológica de Villafañe, permeada por um ou outroflashforward cinematográfico, expressa, antes de mais nada, uma acumulação de práticas e saberes do biografado, não sem as respectivas contradições, hesitações e sombras do passado. A divisão 
da obra em três partes - "Juca Paranhos na sombra do pai (1845-1876)", "A redenção do boêmio (1876-1902)" e "Um saquarema no Itamaraty (1902-1912)" — sugere esse acúmulo linear somente em aparência. Dá-se, então, um barão mais incoerente, vaidoso, obsessivo, ansioso e por vezes cabeça-dura do que aquele dos textos largamente mais hagiográficos de Álvaro Lins (1945) e de Luís Viana Filho (1959).

Afora a revisão sobre a personalidade do barão, as principais contribuições historiográficas - discutidas na terceira e última parte da obra — dizem respeito ao tempo do barão na chefia do Ministério das Relações Exteriores. Villafañe concede especial ênfase a três temas: a interdependência entre política interna e externa, o estabelecimento de uma - suposta - aliança não escrita com os Estados Unidos e a resolução pacífica das disputas lindeiras. São essas as discussões que nos interessam sobremaneira nesta resenha.

Em vez de insistir na oposição entre políticas interna e externa, Villafañe funde-as, vislumbrando a ação diplomática como política pública, cujos entrelaçamentos com os eventos domésticos a explicam, causam e condicionam. De entrada, portanto, há uma revisão pela forma e pelo conteúdo da historiografia diplomática, que, a maneira de textos clássicos, como o de Amado Cervo e Clodoaldo Bueno (2008) ou do mais antigo Delgado de Carvalho (1959), tende a isolar o Itamaraty das tensões políticas internas. Nisso, Villafañe assemelha-se à posição de Rubens Ricupero, marginalmente na rápida biografia do barão que este também escreveu e substancialmente na recente obra sobre o lugar da diplomacia na formação nacional (Ricupero, 2000, 2017). Assim, e para citar apenas alguns exemplos, o barão de Villafañe não conduziu um Itamaraty ausente dos traumas causados pela campanha civilista de Rui Barbosa (1909-1910) ou pela Revolta da Chibata (1910), e foi ativo, em uma chave mais propositiva do que reativa, em seu relacionamento com chefes partidários de magnitude nacional, como Pinheiro Machado.

Se não há negação ontológica entre políticas externa e interna, tampouco haveria, nas ponderações de Villafañe, um Itamaraty autônomo em relação ao governo. O espírito corporativo do ministério, malgrado sua irrefutabilidade, não o tornaria responsável somente perante suas idiossincrasias. Pelo contrário, e em especial na gestão Rodrigues Alves (19021906), o barão esteve longe de ter independência decisória na condução da política externa, inclusive no que se refere a assuntos burocráticos do ministério. Particularmente problemática foi a condução das negociações de limites com a Bolívia, que resultou na assinatura do Tratado de Petrópolis (1903). As concessões feitas pelo barão — nomeadamente, o pagamento de 2 milhões de libras, a construção da ferrovia Madeira-Mamoré e a cessão de pequena parcela territorial - de forma a angariar a posse de um território também disputado, pelo menos em parte, pelo Peru, teriam sido excessivas no olhar de seus principais desafetos. $\mathrm{O}$ tratado, ao qual o barão vinculou, mais à frente, uma áurea de completa vitória, poderia ter ido a pique caso a negociação com o Peru não tivesse sido exitosa. As tratativas com Lima tardaram pouco mais de cinco anos e quase empurraram o Rio de Janeiro para uma guerra 
de resultados incertos. Como se não bastasse, o sucesso alcançado com o Peru deveu-se a fatores exógenos ao Brasil, visto que dependia do laudo arbitral da rival Argentina sobre a fronteira entre o Peru e a Bolívia. Não à toa, a trama que conduziu à assinatura e à ratificação do Tratado de Petrópolis contemplou desentendimentos entre os negociadores brasileiros, como também resistências da imprensa e do governo ao barão do Rio Branco.

Do ponto de vista teórico, e ampliando a discussão sobre a autonomia do Itamaraty na sucessão de governos que marcou a gestão barão e sobre o lugar da chancelaria no tipo de Estado que caracterizou o Brasil da Primeira República, Villafañe não identifica Rio Branco a uma mera expressão dos interesses econômicos dominantes à época, malgrado as irrefutáveis interdependências. Para reabilitar uma antiga discussão metodológico-política da década de 1960, o autor coaduna-se com a interpretação de Nicos Poulantzas (1968), segundo a qual o Estado detém autonomia relativa, agregando-se às contradições de uma restrita pluralidade de classes ou frações de classe economicamente preponderantes, e não forçosamente sucumbindo a uma classe apenas, homogênea e hegemônica. A distinção entre governo e Estado não poderia ser mais importante nesse diapasão. O Itamaraty, indissociável do governo, somente agiria dentro de constrangimentos estruturais impostos pelo tipo de Estado oligárquico constituído especialmente com a presidência de Campos Sales (1898-1902). No concreto, o barão não teria sido um chanceler a serviço de oligarquias cafeeiras perfeitamente coerentes, mas tampouco teria atuado contrariamente a elas. Rio Branco, dito de outra maneira, não tinha margem para opor-se a uma política externa do "café", ou, ainda, ao americanismo característico da Primeira República, mas soube negociar com os atores domésticos - e internacionais, naturalmente - de forma a alcançar o que era possível nos limites daquele momento.

Não por acaso, o americanismo do barão ganha nova interpretação com Villafañe. Não foi o posterior patrono da diplomacia brasileira o primeiro a entabular a virada americanista, que veio com a Proclamação da República. Na mesma lógica dos constrangimentos estruturais, o plano internacional da análise biográfica ganha expressão, e a opção americanista é percebida em uma via de mão de dupla, porém assimétrica. Dada a dependência do setor cafeeiro em relação ao mercado americano - que, de resto, explica pelo menos em grande parte a insistência dos republicanos, já em 1889, pela aproximação com Washington —, a potência então ainda emergente do Norte vislumbrava no Brasil um espaço hemisférico singular para aprofundar sua corrida industrial. Ao chegar à chancelaria, o barão não rompeu com um americanismo alegadamente ingênuo dos primeiros tempos republicanos, mas o aprofundou e o matizou nos limites das estruturas internas e externas. Não há, dessa forma, oposição entre o que haveria sido pejorativamente ideológico e, com o barão, positivamente pragmático, mas uma reinterpretação que enxergava em Washington, a um só tempo, um incontornável espaço comercial e uma garantia para a segurança nacional.

Na leitura de Villafañe, o barão dava compreensão hierárquica às relações hemisféricas, e quanto a isso a proximidade com os Estados Unidos não poderia senão beneficiar o Brasil 
em suas rivalidades regionais, especialmente com a Argentina. Particularmente importantes, na tônica de aproximação, teriam sido as Conferências Pan-americanas do Rio de Janeiro (1906) e de Buenos Aires (1910). Na primeira — não à toa realizada no Palácio Monroe, que se erguia para a ocasião - , o Itamaraty encarregou-se de assinalar aos vizinhos do Brasil uma hipotética e irremediável aliança com os Estados Unidos; na segunda, o barão sugeriu, sem concretizá-lo, um endosso continental à Doutrina Monroe, também como forma de assinalar postura amigável em relação a Washington em um tempo de intensificação, embora relativa, das relações dos Estados Unidos com a Argentina. Malgrado ajustes interpretativos possíveis, conforme se discutirá mais adiante, Villafañe analisa acertadamente os episódios em um quadro de relações não lineares entre Washington e Rio de Janeiro, permeadas por tensões e, sobretudo, pautadas por uma assimetria favorável aos Estados Unidos.

A suposta aliança não escrita com os Estados Unidos cai então rapidamente por terra. A ideia original era de Bradford Burns e foi desenvolvida em contexto histórico de franco interesse brasileiro por uma aproximação irrestrita com Washington (Burns, 1966). Burns, oriundo da Universidade de Califórnia, veio ao Brasil logo após o golpe civil-militar de 1964 e contou com decidido apoio das autoridades nacionais, chegando inclusive a ser condecorado com a Ordem de Rio Branco. A proposta interpretativa, que emoldurava as relações entre o Brasil e os Estados Unidos em um quadro róseo, não se dispôs a elucidar do ponto de vista teórico o sentido de uma aliança não escrita, constituindo-se, pois, em uma seleção de eventos históricos que legitimariam os laços atávicos entre os dois países. Villafañe refuta a interpretação, incluindo na análise momentos de rispidez entre o Brasil e os Estados Unidos tanto no plano bilateral - a exemplo das tensões alfandegárias - quanto no multilateral, à luz do cisma produzido na II Conferência de Paz da Haia (1907).

Integrando a sua análise, então, os momentos difíceis com os Estados Unidos, Villafañe entende que o pensamento diplomático do barão se constituía no tabuleiro complexo das relações internacionais do Brasil. Essa complexidade expressou-se, singular mas não unicamente, nas disputas lindeiras em que Rio Branco esteve envolvido - todas, praticamente, entre 1895 e 1909. Em outras palavras, e aportando documentos novos, como o tratado secreto de aliança militar com o Equador contra o Peru no caso antes referido, Villafañe interpreta as questões de fronteira, incorporando interesses cruzados de Estados direta ou indiretamente envolvidos nas disputas. Os exemplos do Amapá e do Pirara são emblemáticos nesse sentido. No primeiro caso, o litígio entre o Brasil e a França revelou-se bilateral apenas na medida da fronteira contestada e do laudo arbitral. Considerando as tensões sistêmicas próprias à era dos impérios (1870-1914), Villafañe sugere um barão atento às possibilidades de tirar proveito das rivalidades entre a França e a Inglaterra quanto às ambições territoriais desses Estados na América do Sul. O padrão interpretativo, que, em uma adaptação temporal, poderia significar, pelo menos parcialmente, a interdependência complexa de Robert Keohane e Joseph Nye (1977), vale também para o caso da Bolívia — conforme apresentado 
- e para o britânico; quanto ao último, teriam por demais pesado nos insucessos brasileiros na disputa pelo Pirara as pressões de Londres para que o rei da Itália, anglófilo de pulmão cheio por questões territoriais na África, fosse indicado o árbitro contra o Rio de Janeiro.

Metodologicamente rica e coerente - porque alia a nova história política às novas maneiras de biografar - a obra de Villafañe tem tudo para demover aquela que, até agora, tinha sido a principal biografia do barão: a de Álvaro Lins. Não obstante, e da perspectiva de uma crítica interpretativa, alguns episódios poderiam estar mais aprofundados, inclusive para que o sentido geral das principais contribuições historiográficas ganhe expressividade. Penso particularmente, neste espaço restrito próprio às resenhas, em dois momentos e em uma caracterização. No que se refere ao primeiro momento, e na mesma trama dos interesses cruzados, há poucos comentários sobre o discurso de encerramento do barão na III Conferência Pan-Americana do Rio de Janeiro. Disse ele, ao concluir sua fala: "aos países da Europa, a que sempre nos ligaram e hão de ligar tantos laços morais e tantos interesses econômicos, só desejamos continuar a oferecer as mesmas garantias que lhes tem dado até hoje o nosso constante amor à ordem e ao progresso". ${ }^{2}$ Em uma interpretação possível e, ao mesmo tempo, ancorada nos múltiplos tabuleiros do barão, a referência à Europa em plena conferência pan-americana poderia dar-se como sinal de contrapeso a ações imperialistas que também poderiam vir dos Estados Unidos.

O segundo momento que nos interessa, a modo de crítica, diz respeito à IV Conferência Pan-Americana de Buenos Aires. Na leitura de Villafañe, o endosso do barão à Doutrina Monroe teria origem em sua visão de mundo, segundo a qual "o poder de polícia dos Estados Unidos sobre os países instáveis do continente era não somente justificado como desejável" (Santos, 2018, p. 455). Em uma interpretação alternativa, que Villafañe descarta, a posição de Rio Branco seria uma tentativa de multilateralizar a Doutrina Monroe, de forma a ponderar, no continente, sua aplicação (Fonseca Jr., 2012). Parece-me difícil encontrar nos arquivos documento que ratifique a última interpretação; no entanto, julgo-a mais coerente com o pensamento diplomático do barão. Em outros termos, e reciprocamente ao discurso de encerramento na III Conferência, o americanismo do barão expressava-se, embora não exclusivamente, como mecanismo de compensação ao imperialismo europeu. Da mesma forma, a tentativa de construir um triângulo de paz na América do Sul - constituído pela Argentina, pelo Brasil e pelo Chile — também poderia ser vislumbrada como freio político ao vizinho do Norte. Ou, para usar a teoria das relações internacionais, como um instrumento de balancing.

Por último, refiro-me à caracterização de Rio Branco como um saquarema no Itamaraty. $\mathrm{O}$ termo saquarema, menos usual do que o contrário nas fontes primárias, serviu a Ilmar Rohloff de Mattos para designar não apenas o partido conservador, sobretudo nas décadas de 1840

${ }^{2}$ Revista Kosmos, ano III, n. 8, ago. 1906. 
e de 1850, mas também as dimensões sociais e culturais do tipo de Estado que esse mesmo partido havia constituído (Mattos, 1987). Filho de um conservador da segunda geração, o barão talvez tenha carregado, ainda que como contradição, o espírito saquarema que marcou sua formação intelectual. A doutrina do uti possidetis e a das fronteiras naturais, embora de origem colonial, serviram aos saquaremas do Império e ao barão também nos primórdios da República. No entanto, a segunda década republicana em pouco se pareceu ao tempo da direção saquarema (1848-1853), outra expressão de Mattos. O Brasil não tinha sequer a sombra da hegemonia que gozara no Prata; o principal eixo econômico do país havia-se deslocado para São Paulo; a mão de obra não era mais cativa; o Brasil agia multilateralmente, o que o Império abominava; e Washington tomava o posto de Londres. Certo é que o hipotético espírito saquarema do barão poderia emergir fora de seu tempo, mas tampouco é o que nos conta, no fundo, Villafañe. Pelo contrário, e acertadamente, Rio Branco figura em Villafañe como um homem de seu tempo, fazendo história nos limites estruturais do que era então possível.

Saquarema ou, quiçá, republicano malgrélui, o Rio Branco que emerge de Villafañeé, antes de mais nada, um convite aberto ao estudo da história da política externa brasileira. E isso em âmbito universitário, com o qual o autor dialoga, ou para o grande público, constante preocupação no texto agradável, bem-construído, imagético e articulado de Luís Cláudio Villafañe G. Santos.

O autor agradece à Fundação de Amparo à Pesquisa do Estado de São Paulo (FAPESP), processo no $2017 / 12748-0$. 


\section{Referências bibliográficas}

BURNS, Bradford. The unwritten alliance: Rio Branco and Brazilian-American relations. Nova York: Columbia University Press, 1966.

CARVALHO, Delgado de. História diplomática do Brasil. São Paulo: Companhia Editora Nacional, 1959.

CERVO, Amado Luiz; BUENO, Clodoaldo. História da política exterior do Brasil. Brasília: Universidade de Brasília, 2008.

FONSECA JR., Gelson. Rio Branco diante do monroísmo e do pan-americanismo: anotações. In: PEREIRA, Manoel Gomes (Org.). Barão do Rio Branco: 100 anos de memória. Brasília: Funag, 2012.

KEOHANE, Robert; NYE, Joseph S. Power and interdependence: world politics in transition. Boston: Little/Brown, 1977.
LINS, Álvaro. Rio Branco. Rio de Janeiro: Livraria José Olympio Editora, 1945.

MATTOS, Ilmar Rohloff. O tempo saquarema. São Paulo: Hucitec, 1987.

POULANTZAS, Nicos. Pouvoir politique et classes sociales de l'État capitaliste. Paris: François Maspero, 1968.

RICUPERO, Rubens. Barón de Rio Branco. Buenos Aires: Nueva Mayoría, 2000.

. A diplomacia na construção do Brasil. Rio de Janeiro: Versal Editores, 2017.

VIANA FILHO, Luís. A vida do barão do Rio Branco. Rio de Janeiro: Livraria José Olympio Editora, 1959. 